\title{
Empirical Review Analysis of Overview of the Concept of Psychological Capital and Healthcare Employee Behaviours
}

\author{
Elvis Adu ${ }^{1}$, Fanglin $\mathrm{Li}^{1}$, Lucy Boahemaa ${ }^{2}$ Maxwell Opuni Antwi ${ }^{2}$, Ama Boafo-Arthur ${ }^{2,3}$ \\ ${ }^{1}$ School of Finance and Economics, Jiangsu University, 301 Xuefu Road, Zhenjiang, Jiangsu, P.R. China \\ ${ }^{2}$ School of Management, Jiangsu University, 301 Xuefu Road, Zhenjiang, Jiangsu, P.R. China \\ ${ }^{3}$ School of Continuing and Distance Education, University of Ghana, P. O Box LG25, Legon, Accra Ghana \\ Corresponding Author : elvis_adu@ujs.edu.cn
}

\begin{abstract}
The argument is made often times that anytime management shows appreciation of employee's effort, there is a guarantee of high individual performance and job satisfaction, the lack of it, causes severe damage to the economy of the organization and the nation as a whole. The USA alone, there is a budget loss of $\$ 450$ and $\$ 550$ billion dollars due to job dissatisfaction, a phenomenon that transpires highly in the less developed economies especially in the health sector. The WHO reports that in the health service of sub-Saharan Africa, job dissatisfaction on the part of health professionals has been the major reason for health professional's brain drain, which has caused the economies huge sums of money. Essentially, health institutions continue to loose health professionals who complain of dissatisfaction over job or psychological needs frustration which when not addressed, leads to counter productive work behavior that threatens the survival and sustainability of health service delivery. Indeed, the continuous survival of health institutions very much depends on the level of satisfaction employees derive from the job and work environment, which ultimately translates into performance. Research has showed that job satisfaction of health professionals for instance, is crucial for higher performance, motivation and patient satisfaction. However, extant literature reports of low job satisfaction on the part of health professionals in Ghana. This paper presents reviewed work of some authors that are related and of relevance to the study.
\end{abstract}

Keywords : Self-Determination Theory, Autonomy, Relatedness, Competence, Psychological Capital, Autonomy, Psychological Freedom, SDT, ERR

\section{INTRODUCTION}

\section{1) Basic Psychological Needs}

Basic psychological needs are described as the nutriments for proper functioning. These needs central to the self-determination satisfaction of individuals. The basic psychological needs as outlined by the proponents of the Self-Determination Theory are; Autonomy, Relatedness and Competence;
(1) Autonomy Need : Autonomy explained in the selfdetermination theory is quite different from the one expressed in the usual organisation parlance as this requires a superficial commendation. Thus, in a situation where an employee can defend decisions made and the behaviour thereof do so because of a certain level of autonomous motivation achieved. The need for autonomy signifies people innate crave for preference to exercise a sense of choice that assures of psychosomatic freedom in the exercise of their task or 
function (Deci \& Ryan, 2012). Autonomy need in the self-determination theory is conceptually different from the view held in organizational psychology (Morgeson \& Humphrey, 2006). The work of Hackman and Oldham (1976) refer to autonomy as a 'substantial freedom, independence and discretion to the individual in scheduling the work and in determining the procedures to be used in carrying it out' (p. 258). However, self-determination theory describes autonomy as a subjective experience of psychological freedom and choice during activity engagement which is the description given by other scholars in the organizational psychology. Employees might, for instance, follow-up a request from their supervisor (and thus fail to be independent) but nonetheless act willingly because their supervisor provided them a meaningful rationale for doing so (Van den Broeck, Vansteenkiste, De Witte, Soenens, \& Lens, 2010) The feeling of autonomy enable people to see their needs, motivations and inclinations to same as others. Experiencing autonomy gives the impression that people are in control of their lives. In the achievement of autonomy, and at the highest order of reflection, tend to approve their behaviour (Deci \& Ryan, 2012). Humans have the inherent desire to be masters of their own destiny especially in decisions that concern them. This shows that humans will work within their power to satisfy this innate desire as long as they receive needed support from the environment they find themselves in. there is constant relationship between individuals and their environment because in spite of the experience of individuals, (Chen et al., 2015; Chirkov, Ryan, \& Sheldon, 2010) they require the support of their environment to survive and excel in their endeavours. Evidentially, studies have shown that, autonomy need satisfaction leads individuals to experience happiness, become more engaged in their activities and show more interest, (Niemiec, 2013). Conversely lack of need satisfaction lead to frustration, hostilities and destruction (Moller
\& Deci, 2010). This is explained as environment having a greater impact on the behaviour of individuals. People tend express disgust if they fail to receive the required and anticipated support from the environment. Basic need for autonomy get satisfied when there is opportunity for autonomy support through creation of opportunities and or offered selfdirected behaviour. The inherent motivation is developed with elucidations and justifications. Mostly, individuals who enjoy autonomy- support tend to join other people's preferences.

(2) Relatedness Need: The need for relatedness is the desire of individuals to feel the love of people around them. People who enjoy the belongingness in a group and can show it by way of getting their views across and be heard exhibit happiness. Failure to enjoy, dents the confidence and feel a certain lack of selfesteem. The need for relatedness is described as individuals' innate desire to experience connection to others to feel love, belonging, love and care (Baumeister \& Leary, 1995). The need for relatedness is fulfilled only when individuals feel a sense of intimacy and develop warm relationship with people (Deci \& Ryan, 2012). The assumption that individuals have the natural tendency to integrate themselves in the social matrix and benefit from being cared for is equally emphasized in developmental approaches such as Attachment Theory. It is consistent with concepts in organizational psychology such as social support (Viswesvaran, Sanchez, \& Fisher, 1999), and loneliness at work (Kehoe \& Wright, 2013).

(3) Competence Need: Competence as a psychological need is the expressive effect on an individual's social milieu. The need for competence is an inherent desire to acquire the needed expertise to understand the effect exploit. One of the benchmarks for psychological development and well-being is having the competence to detect and stimulate recognition of 
situations. Inability of an individuals to feel control and act effectively makes them have a tumbling experience in their capabilities. Same way, if individuals feel control over their task execution it makes enjoy self-contentment, wellbeing and vitality, (Ryan \& Deci, 2008). For growth and wellness, competence combines effectively to grant the basis for performance. Regardless of situations and circumstances individuals' experience, they have the inner tendency to progress in life. An indication that human being desire to always have control over their situations to achieve their purpose in life (Deci et al., 2017).

In general, all humans strife inherently to attain competence as it is seen as critical for life globally, (Vlachopoulos et al., 2013). Most importantly, getting the needed push from the society individuals live in through responses, it cements the inherent desire. When positive responses are received from colleagues at work, managers and family members, it boosts the competence need in a confident way. However, when the responses become negative from colleagues for instance, the supposed competence reduces drastically which will in turn prevent and mar commitment. It is worth mentioning that, competence need raises perseverance and desire to progress in life which is seen in individuals' interest in activities that test their resilience rather than less interesting activities. In effect, competence need becomes the motivating tool to seek for the ultimate in every situation. The level of challenge a task is brings out the best in individuals and due to this, people prefer to engage in activities that challenges their resilience and are complicated. Satisfying the need for competence given that optimally challenging experiences provide the conditions needed to experience perceived competence and flow. According to Reeve (2014), there are three important ways in which the social environment can help to facilitate perceived competence and flow: (1) providing structure and guidance, (2) relaying information and feedback, and (3) tolerating errors and failures (Reeve, 2014).

Individuals crave for the desire to become controllers of their environment especially workers of an organisation in order to experience the needed work attitudes and to deal with some challenges that come their way. Though competence need has some similarity with self-efficacy but differ based on how they are acquired.

\section{Characteristics of Basic Psychological Need}

Contrary to the views of Maslow and McClelland on need theory, SDT's postulation does not discuss about any particular order through which the needs can be attained.

Secondly, SDT places equal importance on all the three needs. McClelland on the other hand sees needs as something that is acquired by way of socialization and learned. After learning, individuals are praised for what they have been able to acquire and enable them to ascribe feelings of satisfaction.

In contrast, SDT does not focus upon individual differences in need strength, but considers the degree to which people are able to satisfy their fundamental needs as the most important predictor for optimal functioning (Deci \& Ryan, 2014). Consequently, SDT maintains that, for instance, positively perceived feedback is beneficial for all employees as it satisfies their inborn need for competence (Chen et al., 2015).

According to SDT, individuals do not need to experience a deficit for the needs to fuel behaviour. Rather, individuals are attracted to situations in which need satisfaction may occur. Once their needs are satisfied, they are likely to feel energized and to 
actively engage in subsequent need fulfilling activities (Deci \& Ryan, 2012). Consistent with SDT, several studies have shown positive relations between need satisfaction and optimal functioning, both at the interpersonal and intra-individual level (Chen et al., 2015; Deci \& Ryan, 2011) and in general (Lyubomirsky, Dickerhoof, Boehm, \& Sheldon, 2011) as well as across different life-domains. In the context of work, initial evidence was found for positive relations between a composite score of need satisfaction (i.e., aggregated across the three needs) and employees' work-related well-being (i.e., job satisfaction, work engagement, and lower burnout), favourable attitudes (i.e., decreased turn over intentions, increased readiness to change), and higher performance (Gagné \& Vansteenkiste, 2013).

Basic need satisfaction which is work related tend to improve wellbeing and reduce ill-being, (Baard, Deci, \& Ryan, 2004). In a series of studies, researchers continued to confirm the positive relationship with employees' optimal function which is in line with the supposition of the SDT that states of the satisfaction of these three needs contribute to individual in success, Lynch, Plant, \& Ryan, 2005.

Satisfaction of the three needs may, however, relate differently to controlled motivation. According to SDT, controlled motivation results from experiencing external (i.e., a bonus, supervisory approval) or internal (i.e., guilt, shame) contingencies to conduct a particular behaviour. It is contrasted with autonomous motivation, which is prominent when employees engage in an activity because they consider it personally valuable or intrinsically interesting (Deci \& Ryan, 2012). Autonomous motivation correlates positively with, for instance, work-related well-being.

In spite of the fact that basic psychological need satisfaction ensure optimal functioning, it helps in the comprehension of the task of managers and supervisors form of leading Deci et al., 2001 and job characteristics (Van den Broeck et al., 2010) and their relationships with employees' well-being and performance.

\subsubsection{Psychological Capital}

The development of Positive Psychology has been gaining grounds in the Positive Organisational Behaviour literature. A concept Seligman and Csikszentmihalyi (2000) described "as a science of positive subject experience, positive individual traits and positive institutions (which) promises to improve quality of life and prevent the pathologies that arise when life is barren and meaningless" (p.5). This type of idea came into the system not to be a substitute to psychology but to be an accompaniment. It is worth noting that, Positive Psychology plays much premium on examining how things go right instead of focusing on what went wrong. In an attempt to look for a more sustainable and realistic method that is efficient and effective in managing human resource that was becoming complex, practitioners and experts turned to an aspect of Positive Psychology called Psychological Capital (PsyCap). This PsyCap which has four constructs has over the period become an essential source in the Positive Organisational space for predicting job satisfaction and job performance.

Psychological Capital centers on the positive aspects of human nature such as giving of hope, courage, wisdom, responsibility and creativity. The anticipation is that when healthcare professionals are well equipped and developed with some of these positive constructs, it will lead to employees becoming happy and enjoying the work, they do. It is important to note that, (van Wyk, 2013) emphasized on the extent psychological capital offers additive significance and emotions to people contributing to the feeling of ownership in an organization or the larger society. Indeed, psychological capital has been 
defined as the harmonization of personal and organizational characteristics that can be developed and directed, (Luthans \& Youssef, 2007). Research has shown that performance and efficiency of employees and its relationship with psychological emotions have been hypothesized many times (Demir, Ayyildiz Unnu, \& Erturk, 2011).

To be able to understand properly, psychological capital (also known and hereinafter referred to as "PsyCap") has been defined by Avey Avey, Reichard, Luthans, and Mhatre (2011) as an individual's Positive Psychological state of development. For this reason, (Seligman \& Csikszentmihalyi, 2000) introduced the term Positive Psychology, which focuses on looking at the brighter side of human characteristics. It therefore centers on optimism, hope, courage, creativity, responsibility, and power (Luthans \& Youssef, 2007; Reichard, Dollwet, \& Louw-Potgieter, 2014; Richardson \& Guignon, 2008). It is important to mention that it highlights the individual aspects that are positive and are beneficial to the maintenance of mental health. It also goes a long way to ensuring psychological wellness that is idiosyncratic. Hence, Positive Psychology encompasses emotions that are important to the individual that has happened already. This includes satisfaction, something that is now happening, like enjoying of good health and something that is yet to happen, like been in anticipation of a good development, (Avey, Nimnicht, \& Graber Pigeon, 2010).

It is worth noting that the concept of Positive Psychology like any other theory dwells on some assumptions. Firstly, it assumes that humans are active beings who have the capacity to direct their own development. Secondly, there is power in humans that enable them to alter and regulate personal behaviour. Thirdly, it assumes that changing ones behaviour ensures personal motivation
(Durukan Köse, Köse, \& Uğurluoğlu, 2018). It is evident that individuals' motivational issues and personal assessment of situations can be dealt with through the implementation of psychological constructs. These include self-efficacy, optimism, hope and resilience to perk up individual's performance in order to affect motivation, (Cherian \& Jacob, 2013). Consequently, the basis for individual achievement, wellbeing and motivation are addressed by psychological capital construct of selfefficacy. The psychological capital construct of hope explains positive motivational state that allows individuals to reach expected goals, (Peterson et al., 2011). Stimulating individual beliefs that relate with motivation has the capacity to impact positively on the performance of such individuals, (DeDonno \& Demaree, 2008). Self-efficacy and motivation have been found to be forming a central part of job performance that leads to good service quality, effectiveness and efficiency in the work places or organisation, (DeDonno \& Demaree, 2008).

Giving the efficiency in the organizational perspective, scholars describe Positive Psychology as the "works and practice on the strengths and psychological capacity of human resources in order to increase performance" Avey, Nimnicht, et al. (2010) (p. 384). This description gives rise to psychological resources of workers which is seen in self-efficacy, optimism, hope and resilience (Avey et al., 2011; Walumbwa, Luthans, Avey, \& Oke, 2011).

In explaining these PsyCap constructs, self-efficacy concerns itself to employees having the self-belief in their capacity to be successful at what they do in times of difficulty and to be able to mobilize the motivation and cognitive resources to achieve success. Optimism on the other hand denotes constructive expectation of individuals to achieve results in the now and later (Eid, Mearns, Larsson, Laberg, \& Johnsen, 2012; Kinzl et al., 2005). Hope therefore 
involves the state of positivity in terms of individual tendency to the achievement of goals that also includes finding alternative means of reaching those goals. This process involves having the willpower to achieve and identifying the pathways to provide the psychological resources to achieve the needed goals (Paterson, Luthans, \& Jeung, 2014). Further, resilience is explained as the Positive Psychology capacity of an individual to demonstrate positive change and progress in the face of negative situations such as distress and failure (Avey, Nimnicht, et al., 2010; Chang, 2017; Liu et al., 2012). With regards to optimism, individuals envisage a generally better future and positive attribution is connected to personal occurrences, permanent and pervasive causes whereas negative events are attributed to external, temporary and situation-specific events. These constructs have been found to show a higher form of multidimensional resources that show a higher outcome when put together than an addition of the four constructs which also predicts the expected product, (Youssef-Morgan \& Luthans, 2013).

Psychological capital presents managers with the opportunity to develop their employees' because research has shown that individuals who build their PsyCap become confident and are able to succeed in challenges when the needed energy is put in place. Such individuals can make optimistic assertions on how they desire to succeed in their future endeavours and they confidently push towards goals as well as making an appropriate decision when need be. The basic factor that runs through PsyCap is the cognitive, developmental capacity that ensures consistent positive appraisals of circumstances and probability for success based on internalized sense of agency and control that promotes motivated effort and perseverance, (Youssef-Morgan \& Luthans, 2013) PsyCap aligns itself on building the capacity of individuals to bring about Positive Psychology change in them. In Iran, a study was done among 384 Iranian nurses to explore the impact of psychological capital on mental health of nurses considering the mediating role of job burnout. Findings of the research showed that, there is a significant relationship between psychological capital, job burnout and mental health. The study again observed that there was a significant negative relationship between psychological capital and job burnout, and a significant positive relationship between psychological capital and mental health, Estiri, Nargesian, Dastish and Sharifi (2016). Additionally, (Luthans et al., 2007), define PsyCap in terms of four positive state-like capacities: optimism, hope, resilience and self-efficacy are discussed below; Optimism Construct: The desire for attributing a successful endeavour as a way of positively explaining the behaviour is what (Liu et al., 2012) describes as optimism. On the other hand, pessimism is a way of interpreting positive events regarding behaviours that are not permanent and widespread event attribution. Whereas an optimist sees positivity in issues and regards it as temporal, the pessimist always sees negativity in issues and personalize them as permanent situations. Optimism as an idea depends on learned optimism, (Seligman, Steen, Park, \& Peterson, 2005), and people who are dependent experiences optimistic style. Research conducted by Schulman, Keith, and Seligman (1993) on the level of impact of optimism among insurance workers showed that employees who demonstrated great deal of optimistic attitude sold more life insurance than employees that showed little optimism. Additionally, in stressful situations, employees who exhibited more optimism were able to cope more in stressful situations. Extant literature has established that healthcare professionals face a lot of conditions that cause them stress and burnout, (Chou, $\mathrm{Li}, \& \mathrm{Hu}$, 2014; de Paiva, Canário, de Paiva China, \& Gonçalves, 2017; Galletta et al., 2016; NavarroGonzález, Ayechu-Díaz, \& Huarte-Labiano, 2015). It is therefore imperative to develop and build their optimism so they could effectively cope and deal 
efficiently with such situations. In a study by Taylor et al. (2015) to assess the relationship between students' level of stress and optimism, they found that students who showed high level of optimism at the beginning of the semester predicted less stress at end of the semester.

Hope Construct Indeed, hope as a psychological capital construct is defined as the motivational state that directs the perseverance towards desired goals and pathways for success (Liu et al., 2012). Also, according to (Avey et al., 2011) hope is a cognitive process which motivates to find willpower, goal directed determination and way power. In short, it is the planning of ways to meet goals leading to positive emotions and the expectation of meeting desired goals. Furthermore, (Snyder \& Lopez, 2009) defines hope as the liveliness that is centered on the personal goals that lead individuals' to achieve said target. Another significant point is that, in order for individuals to be able to attain specified goals, it necessitates agency and expectations that enable individuals with an "internalized determination and willpower to invest the energy, (Luthans et al., 2007). Undeniably, followers normally take after their leaders and for that reason the level of hope that leaders relay on their employees affect their job satisfaction, performance and motivation, (Adams \& Bond, 2000). Research has established that hope has a positive and significant relationship between job satisfaction, job performance, life satisfaction, (Vallerand, 2012), work satisfaction and performance (Luthans \& Youssef, 2004). Hope encourages the aspirations of positive results and the feel good factor that enables the realization of aim in life and it serves as a reawakening concept that encourages motivation, and to deal with stress, (Çavuş \& Gökçen, 2015). It could be said that it is the mechanism that inspires individuals in their sphere of work. Hope essentially is divided into pathways and agency. Agency is described as the grit that directs the goal whereas pathway depicts the plan to attain the expected goals. (Snyder \& Lopez, 2009) found in his study an additional dimension of hope as agency, pathways and goals where goal was defined as the foremost aspiration to be achieved.

Pathways thinking aims at activating one's mind to look for alternative ways of doing things when there are limited options. It involves focusing on positive attitude to reaching the ultimate through self-talk. Agency thinking also aims at activating one's will power to motivate oneself not to give up. It becomes necessary when one begins to realise high motivation to alternative pathways. Though Hope may overlap into other psychological constructs, like optimism and self-efficacy, because they show akin slant toward achieving a set goal, they should be seen as complimenting each other.

Resilience Construct: Another significant construct of the psychological capital is seen in the light of individuals having the willingness to bounce back after suffering a setback, (Liu et al., 2012). Some of the characteristics that define individuals with resilience include having a positive outlook, seeing changes in any aspect of life as another challenge to surmount. Others include those who always want to be involved in the action, communicate their needs to people who need to know and can provide the support they require (Spangler, Koesten, Fox, \& Radel, 2012). Added to this are those who attempt to improve their employability by focusing on asset techniques and risk- focused techniques that impacts on the interpretation of adverse events, (Luthans \& Youssef, 2007). Positively, individuals who exhibit resilience show coping strengths in dealing with stress in a continuously changing environment, (Raza-Ullah, Bengtsson, \& Kock, 2014; Tugade, Fredrickson, \& Feldman Barrett, 2004). Further, individuals who demonstrate high resilience also show a lot of emotional stability in times of trouble 
and challenges. Sun, Xiao, Li and Li (2011) did a study among nurses in university hospitals on the relationships between psychological capital, job embeddedness and performance. The study found that there was a strong relationship between the self-reported psychological capital, job embeddedness and performance of the nurses. Additionally, Li, Chang, Wang and Wang (2012) researched into how psychological capital (PsyCap) mediates the association between occupational stress and depressive symptoms among Chinese physicians. The authors observed gender difference in the mediating role of PsyCap on the occupational stress-depressive symptoms association. For male physicians, PsyCap did not mediate the association between occupational stress and depressive symptoms. For female physicians, ERR and over-commitment were negatively associated with PsyCap, and PsyCap was negatively associated with depressive symptoms. As a result, PsyCap significantly mediated the associations of ERR and over-commitment with depressive symptoms.

Self-Efficacy Construct: Thus, self-efficacy is based on the work of Bandura and Wessels (1997) in his social cognitive theory. It refers to the capacity of individuals to express a positive self-belief on their abilities to succeed in a challenging situation, (Liu et al., 2012). Concerning characteristics, individuals who exhibit high self-efficacy can generate challenges and set their own goals to overcome those challenges. In addition, they are able to endure difficult times until they succeed (Liu et al., 2012). Some of the activities that can enhance the self-efficacy of individuals include but not limited to provision of positive feedback, psychological and physiological arousal and vicarious learning, (Luthans et al., 2007). A study that sought to find out the relationship between self-efficacy and work stress among preservice teachers found that there was increasing selfefficacy, which was significant vis-à-vis significant decrease in the stress level of the teachers, (Klassen \& Durksen, 2014). In effect, the higher the selfefficacy, the lower the stress level of individuals. It is therefore important that self-efficacy be developed among healthcare professionals to deal with their lower motivation and increase their selfdetermination.

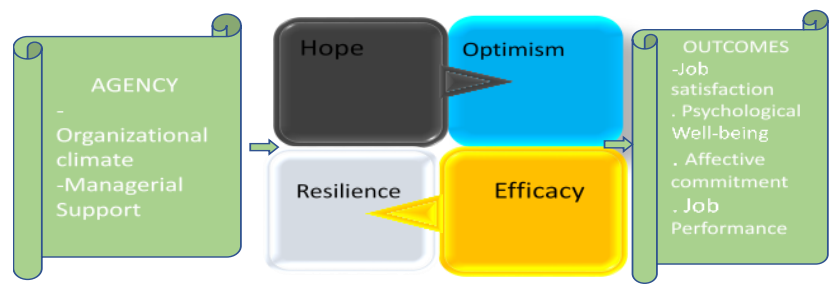

Figure 2. 1 Overview of the Concept of Psychological Capital

\subsubsection{Job Related Attitudes}

This section discusses the various job related attitudes among health care professionals that were considered in this study. It includes, job satisfaction, psychological well-being, job involvement and affective commitment.

\section{(1) Job Satisfaction}

Job satisfaction is a widely used concept in both scientific research and in daily lives, but scholars are yet to agree on any final definition of what job satisfaction is since various authors see it differently. It is referred to as employees' cognitive evaluation of their job (Bakker \& Oerlemans, 2011). Additionally, Locke (1969) defined job satisfaction as "the pleasurable emotional state resulting from the appraisal of one's job as achieving or facilitating the achievement of one's job values" (p. 316). In the view of Hoppock, job satisfaction is the combination of psychological, physiological and environmental conditions that enable an individual to proclaim satisfaction of job, while Vroom described it as looking at the work roles that employees occupy. However, Spector (1997) defines job satisfaction concentrating on the feeling of the employee about the job coupled with other facets that includes the 
likes and dislikes about the job, (Aziri, 2011). In short, it is a worker's sense of achievement and success on the job. The general perception is that, it directly links to productivity and personal well-being. Job satisfaction implies doing a job one enjoys, doing it well and being rewarded for one's efforts. It further implies enthusiasm and happiness with one's work and it is the key ingredient that leads to recognition, income, promotion, and the achievement of other goals that lead to a feeling of fulfilment (Kaliski, 2007) cited in Aziri (Aziri, 2011). According to Yami, Hamza, Hassen, Jira, and Sudhakar (2011), job satisfaction of health workers in developing countries in general is very low, it is the reason we seek to establish in our study, the role of psychological capital in maintaining and explaining job satisfaction to sustain performance. Basically because, studies have shown that quality of healthcare delivery lies in the level of satisfaction employees align with jobs, (Abdulla, 2019; Sutikno, 2019). More so, different authors have corroborated the fact that there is a direct relationship between job satisfaction and performance, a finding Nabirye, Brown, Pryor, and Maples (2011) posit that it is a happening that is perceived globally. This phenomenon seems bidirectional because other researchers like (Biswakarma, 2016) have found that perceived job performance also influences job satisfaction of employees when it is given organizational support. Research has showed that job satisfaction of health professionals is crucial for higher performance, motivation and patient satisfaction. However, extant literature reports of low job satisfaction on the part of health professionals in Ghana, (Acquah, 2018; Agyepong et al., 2004; Kwamie et al., 2014)

\section{REFERENCES}

[1]. Soenens, B., Sierens, E., Vansteenkiste, M., Dochy, F., \& Goossens, L. (2012). Psychologically controlling teaching: Examining outcomes, antecedents, and mediators. Journal of Educational Psychology, 104(1), 108.

[2]. Spangler, N. W., Koesten, J., Fox, M. H., \& Radel, J. (2012). Employer perceptions of stress and resilience intervention. Journal of occupational and environmental medicine, 54(11), 1421-1429.

[3]. Spector, P. E. (1997). Job satisfaction: Application, assessment, causes, and consequences (Vol. 3): Sage publications.

[4]. Srinivasan, M. (2011). An Integral Approach to Talent Management. Vilakshan: The XIMB Journal of Management, 8(2).

[5]. Stajkovic, A. D., \& Luthans, F. (1998). Self-efficacy and work-related performance: A meta-analysis. Psychological bulletin, 124(2), 240.

[6]. Standage, M., Duda, J. L., \& Ntoumanis, N. (2003). A model of contextual motivation in physical education: Using constructs from selfdetermination and achievement goal theories to predict physical activity intentions. Journal of educational psychology, 95(1), 97.

[7]. Starza-Smith, A., Beveridge, A., \& Talbot, E. (2019). C-52 Neuropsychological Sequelae of Hypernatraemic Dehydration in NeonatesWorking Towards the NHS England Five Year Forward View. Archives of Clinical Neuropsychology, 34(6), 1081-1081.

[8]. Steel, B. S., Pierce, J. C., Berman, E., \& Taylor, J. (2017). Job satisfaction in Cascadia: A comparison of British Columbia, Oregon, and Washington civil servants. The Social Science Journal, 54(4), 379-388.

[9]. Steenkamp, J.-B. E., \& Baumgartner, H. (2000). On the use of structural equation models for marketing modeling. International Journal of Research in Marketing, 17(2-3), 195-202.

[10]. Stone, D. N., Deci, E. L., \& Ryan, R. M. (2009). Beyond talk: Creating autonomous motivation through self-determination theory. Journal of General Management, 34(3), 75-91.

[11]. Suliman, A. M. (2002). Is it really a mediating construct? The mediating role of organizational commitment in work climate-performance 
relationship. Journal of Management Development, 21(3), 170-183.

[12]. Sutikno, A. E. (2019). EXPECTATION BASED REWARD SYSTEM FOR REDUCING EMPLOYEES'TARDINESS. Jurnal Administrasi Kesehatan Indonesia, 7(1), 9-17.

[13]. Tabachnick, B. G., \& Fidell, L. S. (2001). Principal components and factor analysis. Using multivariate statistics, 4, 582-633.

[14]. Taris, T. (2002). BM Byrne, Structural equation modeling with AMOS: Basic concepts, applications, and programming Mahwah NJ: Lawrence Erlbaum, 2001 0-8058-3322-6. European Journal of Work and Organizational Psychology, 11, 243-246.

[15]. Taylor, S. J., Bogdan, R., \& DeVault, M. (2015). Introduction to qualitative research methods: A guidebook and resource: John Wiley \& Sons.

[16]. Terera, S. R., \& Ngirande, H. (2014). The impact of rewards on job satisfaction and employee retention. Mediterranean Journal of Social Sciences, 5(1), 481.

[17]. Thompson, C. A., \& Prottas, D. J. (2006). Relationships among organizational family support, job autonomy, perceived control, and employee well-being. Journal of occupational health psychology, 11(1), 100.

[18]. Thompson, E. R., \& Phua, F. T. (2012). A brief index of affective job satisfaction. Group \& Organization Management, 37(3), 275-307.

[19]. Trépanier, S.-G., Fernet, C., \& Austin, S. (2013). Workplace bullying and psychological health at work: The mediating role of satisfaction of needs for autonomy, competence and relatedness. Work \& Stress, 27(2), 123-140.

[20]. Tugade, M. M., Fredrickson, B. L., \& Feldman Barrett, L. (2004). Psychological resilience and positive emotional granularity: Examining the benefits of positive emotions on coping and health. Journal of personality, 72(6), 1161-1190.

[21]. Turner, N., Barling, J., \& Zacharatos, A. (2002). Positive psychology at work. Handbook of positive psychology, 52, 715-728.
[22]. Tziner, A., Rabenu, E., Radomski, R., \& Belkin, A. (2015). Work stress and turnover intentions among hospital physicians: The mediating role of burnout and work satisfaction. Revista de Psicología del Trabajo y de las Organizaciones, 31(3), 207-213.

[23]. Ullman, J., \& Bentler, P. (2003). Structural Equation Modeling. Hoboken: NJ: Wiley Online Library.

[24]. Unanue, W., Dittmar, H., Vignoles, V. L., \& Vansteenkiste, M. (2014). Materialism and well-being in the UK and Chile: Basic need satisfaction and basic need frustration as underlying psychological processes. European Journal of Personality, 28(6), 569-585.

[25]. Uysal, A., Lee Lin, H., \& Raymond Knee, C. (2010). The role of need satisfaction in selfconcealment and well-being. Personality and social psychology bulletin, 36(2), 187-199.

[26]. Vallerand, R. J. (2012). The role of passion in sustainable psychological well-being. Psychology of well-Being: Theory, research and practice, 2(1), 1.

[27]. van den Berg, T. I., Alavinia, S., Bredt, F. J., Lindeboom, D., Elders, L. A., \& Burdorf, A. (2008). The influence of psychosocial factors at work and life style on health and work ability among professional workers. International archives of occupational and environmental health, 81(8), 1029-1036.

[28]. Van den Broeck, A., Vansteenkiste, M., De Witte, H., Soenens, B., \& Lens, W. (2010). Capturing autonomy, competence, and relatedness at work: Construction and initial validation of the Work-related Basic Need Satisfaction scale. Journal of Occupational and Organizational Psychology, 83(4), 981-1002.

[29]. van der Doef, M., Mbazzi, F. B., \& Verhoeven, C. (2012). Job conditions, job satisfaction, somatic complaints and burnout among East African nurses. Journal of clinical nursing, 21(11-12), 1763-1775. 
[30]. van Gelderen, B. R., \& Bik, L. W. (2016). Affective organizational commitment, work engagement and service performance among police officers. Policing: An International Journal of Police Strategies \& Management, 39(1), 206-221.

[31]. van Wyk, R. (2013). The manifestation of familiness resources and psychological capital as familiness capital: A conceptual analysis. The International Business \& Economics Research Journal (Online), 12(9), 1021.

[32]. Vansteenkiste, M., \& Ryan, R. M. (2013). On psychological growth and vulnerability: basic psychological need satisfaction and need frustration as a unifying principle. Journal of psychotherapy integration, 23(3), 263.

[33]. Vaske, J. J., Beaman, J., \& Sponarski, C. C. (2017). Rethinking internal consistency in Cronbach's Alpha. Leisure Sciences, 39(2), 163-173.

[34]. Viswesvaran, C., Sanchez, J. I., \& Fisher, J. (1999). The role of social support in the process of work stress: A meta-analysis. Journal of Vocational Behavior, 54(2), 314-334.

[35]. Vlachopoulos, S. P., Asci, F. H., Cid, L., Ersoz, G., González-Cutre, D., Moreno-Murcia, J. A., \& Moutão, J. (2013). Cross-cultural invariance of the basic psychological needs in exercise scale and need satisfaction latent mean differences among Greek, Spanish, Portuguese and Turkish samples. Psychology of sport and exercise, 14(5), 622-631.

[36]. Walumbwa, F. O., Luthans, F., Avey, J. B., \& Oke, A. (2011). Retracted: Authentically leading groups: The mediating role of collective psychological capital and trust. Journal of organizational behavior, 32(1), 4-24.

[37]. White, M., \& Bryson, A. (2019). The Impact of High-Performance Work Systems on Employees: A Sectoral Comparison: Department of Quantitative Social Science-UCL Institute of Education ....

[38]. Wihlborg, J., Sivberg, B., Johansson, A., \& Edgren, G. (2016). Clinicians' Perceptions of Teaching and Learning-Challenges and Possibilities. Paper presented at the NETNEP 2016-6th International Nurse Education Conferense.

[39]. Williams, L. J., \& Anderson, S. E. (1991). Job satisfaction and organizational commitment as predictors of organizational citizenship and inrole behaviors. Journal of Management, 17(3), 601-617.

[40]. Wright, T. A. (2010). More than meets the eye: The role of employee well-being in organizational research Oxford handbook of positive psychology and work.

[41]. Wright, T. A., \& Bonett, D. G. (2007). Job satisfaction and psychological well-being as nonadditive predictors of workplace turnover. Journal of management, 33(2), 141-160.

[42]. Wright, T. A., \& Cropanzano, R. (2000). Psychological well-being and job satisfaction as predictors of job performance. Journal of occupational health psychology, 5(1), 84.

\section{Cite this article as :}

Elvis Adu, Fanglin Li, Lucy Boahemaa, Maxwell Opuni Antwi, Ama Boafo-Arthur, "Empirical Review Analysis of Overview of the Concept of Psychological Capital and Healthcare Employee Behaviours", International Journal of Scientific Research in Science and Technology (IJSRST), Online ISSN : 2395-602X, Print ISSN : 23956011, Volume 6 Issue 6, pp. 93-103, NovemberDecember 2019. Available at doi : https://doi.org/10.32628/IJSRST196612

Journal URL : http://ijsrst.com/IJSRST196612 